\title{
Association mapping reveals novel serpentine adaptation gene clusters in a population of symbiotic Mesorhizobium
}

\author{
Stephanie S Porter ${ }^{1}$, Peter L Chang ${ }^{2,3}$, Christopher A Conow ${ }^{2}$, Joseph P Dunham ${ }^{2}$ and \\ Maren L Friesen ${ }^{4}$ \\ ${ }^{1}$ School of Biological Sciences, Washington State University, Vancouver, WA, USA; ${ }^{2}$ Section of Molecular and \\ Computational Biology, Department of Biological Sciences, University of Southern California, Los Angeles, \\ CA, USA; ${ }^{3}$ Department of Plant Pathology and Nematology, University of California, Davis, CA, USA and \\ ${ }^{4}$ Department of Plant Biology, Michigan State University, East Lansing, MI, USA
}

\begin{abstract}
The genetic variants that underlie microbial environmental adaptation are key components of models of microbial diversification. Characterizing adaptive variants and the pangenomic context in which they evolve remains a frontier in understanding how microbial diversity is generated. The genomics of rhizobium adaptation to contrasting soil environments is ecologically and agriculturally important because these bacteria are responsible for half of all current biologically fixed nitrogen, yet they live the majority of their lives in soil. Our study uses whole-genome sequencing to describe the pangenome of a focal clade of wild mesorhizobia that show contrasting levels of nickel adaptation despite high relatedness (99.8\% identity at $16 \mathrm{~S})$. We observe ecotypic specialization within an otherwise genomically cohesive population, rather than finding distinct specialized bacterial lineages in contrasting soil types. This finding supports recent reports that heterogeneous environments impose selection that maintains differentiation only at a small fraction of the genome. Our work further uses a genome-wide association study to propose candidate genes for nickel adaptation. Several candidates show homology to genetic systems involved in nickel tolerance and one cluster of candidates correlates perfectly with soil origin, which validates our approach of ascribing genomic variation to adaptive divergence.
\end{abstract}

The ISME Journal (2017) 11, 248-262; doi:10.1038/ismej.2016.88; published online 15 July 2016

\section{Introduction}

A central challenge in microbial evolutionary ecology is identifying genomic variation responsible for environmental adaptation. Local adaptation results when environment-specific selection is stronger than migration and builds local reservoirs of genetic diversity within a population's biogeographic structure (Martiny et al., 2006; Reno et al., 2009; Hanson et al., 2012; Cordero et al., 2012b; Cordero and Polz, 2014; Shapiro and Polz, 2014). Current models of microbial diversification require selection for habitat-specific adaptive variants leading to the formation of stable genomic clusters, that is, 'ecotypes' (Konstantinidis and Tiedje, 2005; reviewed in Polz et al., 2013; Shapiro and Polz, 2014). In genomewide sweeps, environmental selection causes clonal

Correspondence: ML Friesen, Department of Plant Biology, Michigan State University, 612 Wilson Rd, East Lansing, MI 48824, USA.

E-mail: mfriesen@msu.edu

Received 3 January 2016; revised 23 May 2016; accepted 25 May 2016; published online 15 July 2016 expansion of the first genome that acquires an adaptive variant (Cohan, 2002; Shapiro and Polz, 2014). Sweeps initially lower diversity, which is replenished by subsequent mutations (Shapiro and Polz, 2014). In contrast, gene-specific sweeps occur when recombination across habitats erodes genomewide linkage with environment-specific adaptive variants (Cordero et al., 2012b; Shapiro et al., 2012; Polz et al., 2013; Shapiro and Polz, 2014; Rosen et al., 2015). Empirical genomic data supporting these different paths to microbial ecotypic diversification are relatively sparse (Polz et al., 2013; Cordero and Polz, 2014; Shapiro and Polz, 2014). Thus, characterizing adaptive variants and their genomic context remains a key frontier (Shapiro et al., 2009; Zaneveld et al., 2011).

A transformative insight from high-throughput bacterial population genome sequencing (Stapley et al., 2010; Zaneveld et al., 2011) is that closely related strains share a core genome but that each has a suite of varying accessory (flexible) genes (Reno et al., 2009; Polz et al., 2013); collectively these make up the pangenome (Kettler et al., 2007; Lapierre and Gogarten, 2009; Reno et al., 2009; Denef et al., 2010a). If genome- 
wide linkage is low, variation in the core and accessory genomes may have distinct biogeographical patterns. For example, the core genomes of Rhizobium leguminosarum (Kumar et al., 2015) and Vibrio cholerae (Boucher et al., 2011) are globally well-mixed, while the accessory genome is ecologically differentiated. The core genome encodes basic functions necessary for the common niche of the sampled isolates (Lapierre and Gogarten, 2009; Polz et al., 2013). Adaptation via the core genome could be constrained by slow rates of nucleotide substitution or genome-wide selective sweeps (Gevers et al., 2005; Cohan and Perry, 2007). However, adaptive alleles within the core genome demonstrate that recombination can act rapidly enough for gene-level sweeps to occur in response to temperature and latitude (terrestrial fungus Neospora; Ellison et al. (2011)), and substrate particle size (marine Vibrio bacteria; Shapiro et al. (2012)). The accessory genome, with its shifting complement of genes that can be lost or gained via horizontal transfer (Polz et al., 2013), is considered the primary reservoir of microbial adaptive variation, as well as containing transient, non-adaptive genes (Kuo and Ochman, 2009; Lapierre and Gogarten, 2009; Andam and Gogarten, 2011; Smillie et al., 2011). Adaptive accessory genes have been identified for phosphorus availability (marine Prochlorococcus and Pelagibacter; Coleman and Chisholm (2010)) and successional context (acid mine drainage Leptospirillum bacteria; Denef et al. (2010a)). An environment-specific horizontally transmitted accessory gene pool can connect otherwise unrelated strains (reviewed in Polz et al., 2013).

Recent work presented a collection of locally adapted wild Mesorhizobium strains across naturally nickel-enriched serpentine soils paired with nearby low-nickel soils (Porter and Rice, 2013). Rhizobia are an accessible population because they disperse through soil between generations of symbiotic association with their host plant (here, Acmispon wrangelianus) and are readily culturable in the laboratory (Sprent, 2007; Oldroyd et al., 2009). Heavy metal enrichment and unusual ionic ratios in both natural serpentine soils (Brady et al., 2005; Turner et al., 2010) and anthropogenic mine spoils (McNeilly, 1968) can drive local adaptation in plants. While rhizobia are often sensitive to heavy metals (Giller et al., 2009), these Mesorhizobium exhibit local adaptation to nickel in culture: strains originating from high-nickel serpentine soil had higher fitness under high-nickel levels than strains originating from low-nickel non-serpentine soil, and strains originating from non-serpentine soil had higher fitness in low-nickel media than strains from serpentine (Porter and Rice, 2013).

We use whole-genome sequencing to describe the pan-genome of a focal clade of mesorhizobia that show contrasting levels of nickel adaptation. We describe how spatial distance and soil type structure the core and accessory genomes. Using a genome- wide association study, we identify genomic variants that are statistically associated with strain growth in nickel-containing medium and compare these with known heavy metal resistance mechanisms (Sa-Pereira et al., 2009; Mengoni et al., 2010). We ask whether adaptive variants (i) reside in the core or accessory genome, (ii) are clustered and (iii) are shared with distantly related lineages.

\section{Materials and methods}

Mesorhizobium strains with varying responses to nickel were isolated from field-collected $A$. wrangelianus root nodules by Porter and Rice (2013) (Figure 1) from serpentine soil, which is naturally enriched in toxic levels of nickel (3.1-86.5 mg $\mathrm{Ni} \mathrm{kg}^{-1}$ ), and from spatially adjacent nonserpentine soils containing lower levels of nickel (0.8-6.85 mg Ni kg-1) at each of three Californian reserves (Figure 1). We selected 38 strains from a focal $16 \mathrm{~S}$ subclade (99.8\% identity over $1340 \mathrm{bp}$ ) present in both soil types and all three reserves that exhibit adaptation to soil nickel, as well as 9 strains that captured the diversity of sympatric Mesorhizobium clades (Figure 1a). Within the focal clade, serpentine strain fitness is higher than nonserpentine strain fitness under high nickel $\left(\mathrm{F}_{1,34}=78.4, P<0.0001\right.$; Figure $\left.1 \mathrm{c}\right)$, while serpentine and non-serpentine strain fitness is similar under low nickel (Figure 1). Supplementary Information 1 contains additional details regarding methods.

DNA extraction and genomic library construction followed Dunham and Friesen (2013). Libraries were sequenced in a paired $76 \mathrm{bp}$ format on an Illumina GAIIx (San Diega, CA, USA). Draft genomes were assembled with the A5 pipeline (Tritt et al., 2012). Genes were annotated using a two-stage procedure. First, draft genomes were searched for 'reference' genes homologous to 7272 protein-coding sequences in the complete Mesorhizobium huakuii bv. loti MAFF303099 genome (BLASTX alignment with $>80 \%$ overlap, $E$-value $<1 \mathrm{E}-20$, and protein sequence identity $>50 \%$ ). Next, we identified 'de novo' genes in the wild strains that were absent in M. huakuii bv. loti. Regions of the draft assemblies that did not contain reference genes were aligned using BLASTX to the nonredundant GenBank CDS translations+PDB+Swiss-Prot + PIR+PRF (nr) database using the same BLASTX parameters. Orthology among de novo genes was determined using reciprocal BLAST (Supplementary Information 1). Annotation was conducted with Blast2GO v.2.3.5 (Conesa et al., 2005) and UniProt (UniProt Consortium, 2015).

'Core' genes are present in all strains for a given subset (focal clade: 38 strains; full wild set: 47 strains; full set with references: 53 strains). 'Accessory' genes are absent from one or more strain in each subset. Delineation of core and accessory was calculated for each of the three subsets. For genes in the core genome across all 53 strains, we performed 


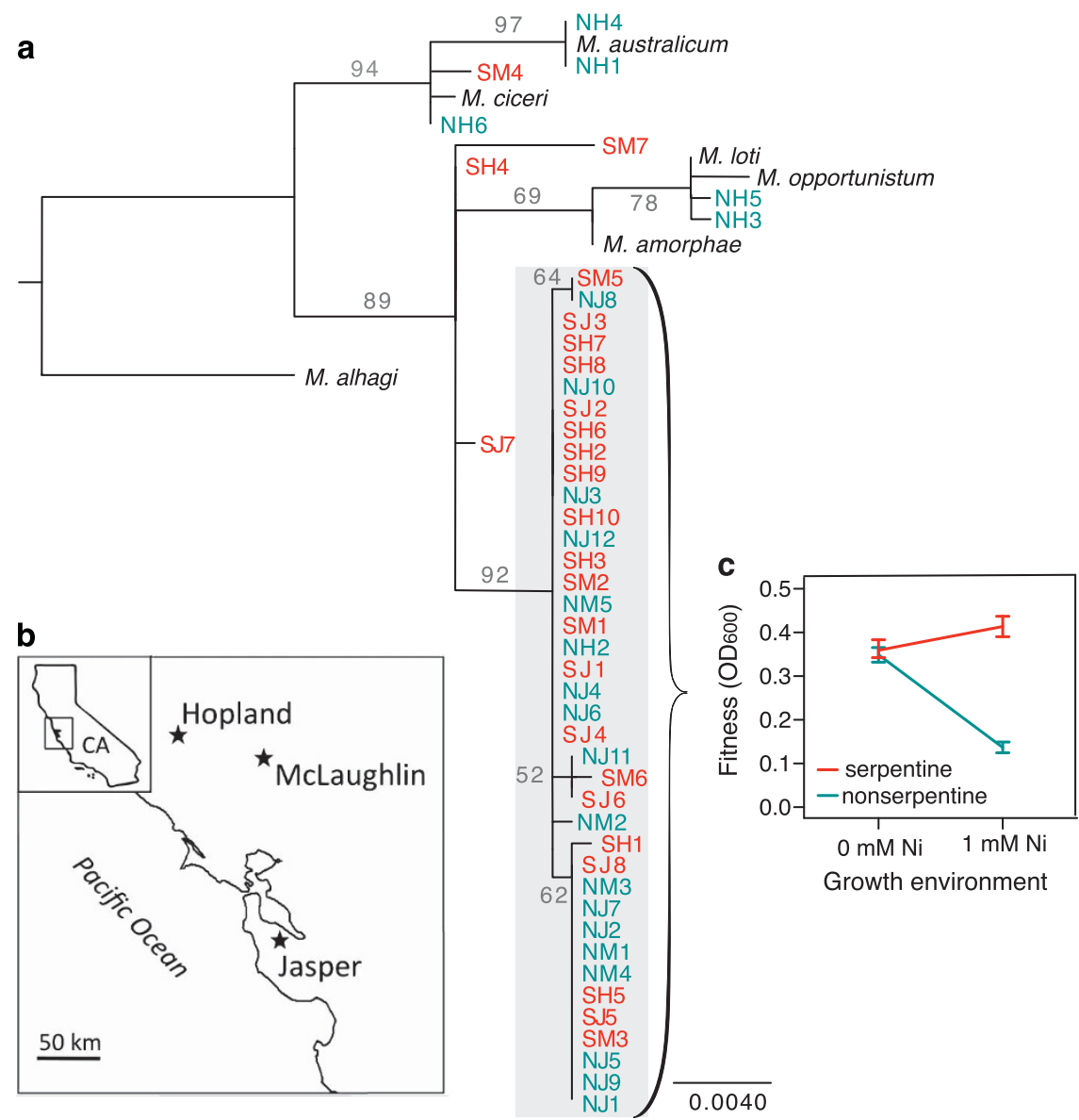

Figure 1 Differential nickel adaptation in wild Mesorhizobium. (a) Phylogenetic tree based on 16S Sanger sequence data, with bootstrap values (teal: serpentine; red: non-serpentine soil of origin; gray background: focal clade). (b) Collection sites in California (CA) (star: a reserve where adjacent serpentine and non-serpentine soils were sampled). (c) Growth data for strains from the focal clade in the presence and absence of nickel in liquid media $\left(\mathrm{OD}_{600}\right.$ : optical density at $\left.600 \mathrm{~nm}\right)$.

multiple sequence alignments to identify singlenucleotide polymorphisms (SNPs) (ClustalW; Larkin et al., 2007). Simulation verified the efficacy of our methods in identifying accessory genes (Supplementary Figure S1).

To compare core and accessory genomes, we calculated GO enrichment tests ( $\mathrm{R}$ Bioconductor package 'GOstats'; Falcon and Gentleman (2007)) and rates of non-synonymous (Ka) to synonymous (Ks) substitution (KaKs Calculator; Zhang et al., 2006). Strain relatedness was assessed using core genome allelic variation and accessory gene presence/absence. We used a population-based perspective allowing horizontal gene transfer implemented by NeighborNet (SplitsTree v4.12.8; Huson, 1998, 2005).

To analyze biogeographic patterns we used 'adonis' in the R package 'vegan' (Dixon, 2003) with bootstrapping. To infer population structure and probabilistically assign individuals to populations, we ran STRUCTURE v2.3.2.1 (Pritchard et al., 2000) on each of 10 replicate SNP subsets sampled every 25 SNPs. We used delta $\mathrm{K}$ with $\mathrm{K}$ ranging from 1 to 8 (Evanno et al., 2005).
We conducted genome-wide association mapping (Friesen and von Wettberg, 2010) of growth in the presence of nickel for (i) gene content in the accessory genome, and (ii) SNPs in the core genome, excluding singletons and regressing out STRUCTURE effects (see Supplementary Information 1). Significance of the Wilcoxon test was assessed using Bonferroni correction and false discovery rates (FDR) (Hochberg and Benjamini, 1990). Candidates were further annotated using TrEMBL and Swiss-Prot. We examined draft genome contigs containing FDR $<0.10$ candidates to assess clustering of candidate genes. A cluster was defined as a region on a single contig with at least four tandem candidate genes, and expanded to include nearby candidate genes until no candidate gene was found for $10 \mathrm{~kb}$ on either end.

We tested whether candidate accessory genes are shared with lineages that are more phylogenetically distant from the focal clade than expected by chance. For each accessory gene, we identified the lineage bearing the closest homolog in Genbank and calculated the distance between this bacteria and the focal clade at $16 \mathrm{~S}$. We compared the distribution of 
distances for candidate vs non-candidate accessory genes using a KS test.

\section{Results}

\section{Population pan-genomics}

We characterized the pan-genome of 47 strains of wild symbiotic Mesorhizobium isolates collected across replicated serpentine and non-serpentine Californian soils (Figure 1). Draft genomes ranged in size from 5.75 to $7.79 \mathrm{Mbp}$ (median 6.61 Mbp; Supplementary Table S1). Assemblies used from $95 \%$ to $98 \%$ of filtered reads for a median coverage of $70 \times(42-130 \times)$. The number of genes identified in each draft genome ranged between 5454 and 6725, with a median of 6078. Draft genomes had a median of 56.5 contigs (21-273) and median N50 of $358 \mathrm{kbp}$ (129-911 kbp).

Across our 47 wild strains, genes tended to be rare or ubiquitous (Figure 2a). Across our 47 wild strains and 6 fully sequenced relatives, 27802 genes are present in at least one strain with 2059 core genes in all 53 strains (Figure 2b). Wild Californian strains have a pan-genome containing 20582 genes and a core genome of 2874 genes, while our focal clade has a pan-genome of 13049 genes and a core genome of 4308 genes (Figure 2b). Within the core genome of the complete set of 53 strains, there were 1106970 segregating SNPs called in all strains; 212192 of these varied within the focal clade and were used for phenotype associations.

Core and accessory genomes exhibit contrasting patterns of functional enrichment and molecular evolution. Compared with the core genome, accessory genes show the strongest enrichment for the molecular function, nucleotide binding (GO:0003676: all strains $P=4.42 \mathrm{E}-10$; wild strains $P=8.51 \mathrm{E}-13$ ), and the biological process, DNA metabolism (GO:0006259: all strains $P=1.45 \mathrm{E}-36$; wild strains $P=2.36 \mathrm{E}-49$ ). The accessory genome is also strongly enriched in DNA recombination (GO:0006310: all strains $P=1.37 \mathrm{E}-35$; wild strains $P=2.69 \mathrm{E}-50$ ), with all but one gene annotated with this term located in the accessory genome (all strains 528/529 genes; wild strains 430/431 genes). Finally, the accessory genome is enriched in cellular compartment terms related to the cell membrane, including membrane (GO:0016020: all strains $P=1.42 \mathrm{E}-23$; wild strains $P=6.08 \mathrm{E}-20$ ), intrinsic to membrane (GO:0031224: all strains $P=7.43 \mathrm{E}-10$; wild strains $P=1.64 \mathrm{E}-05)$ and membrane part (GO:0044425: all strains $P=8.33 \mathrm{E}-09$; wild strains $P=5.24 \mathrm{E}-05)$ (Supplementary Table S2).

Compared with the core genome, the accessory genome showed elevated rates of protein sequence evolution relative to genome sequence change, reflected in the ratio of non-synonymous to synonymous substitutions (Wilcoxon rank sum test on log10 values: $W=4337428, P<2.2 \mathrm{E}-16$; Figure 2c).

Using NeighborNet, the core genome of the focal clade of 38 strains is divergent from six fully sequenced Mesorhizobium strains as well as the remaining 9 wild strains (Figure 3). NeighborNet trees show more reticulation in the gene content network than the SNP network (Figure 3). However, SNPs in the core genome and variation in the accessory genome show congruent topologies (Figure 3). Furthermore, both core and accessory genome variation show that the focal clade subnet is approximately a star with little deep structure and no strong signal of soil type or reserve (Figure 3).

STRUCTURE and the delta $\mathrm{K}$ method demarcate two clusters within the 47 wild strains, with the focal clade distinct from the more distantly related strains. Within the focal clade, there is weak genomic structuring among collection locations and soil types. STRUCTURE analysis revealed two subgroups within the focal clade core genome (Supplementary Figure S2 and Supplementary Table S3). Divergence within the focal clade is not split cleanly by soil type or geographic separation: averaged over multiple STRUCTURE runs, the minority STRUCTURE subgroup contains five fully assigned strains from serpentine soil from Jasper Ridge and Hopland and one $92.8 \%$ assigned strain from non-serpentine soil from Jasper Ridge. Other strains contained 0.011-38.0\% of the minority cluster (Supplementary Figure S2). Nonparametric analysis of variance revealed that a significant but relatively small amount of genetic variation is explained by reserve (a proxy for geographic distance) and soil type (Supplementary Figure S3). This analysis also revealed that soil type explains more of the variance in the accessory genome than in
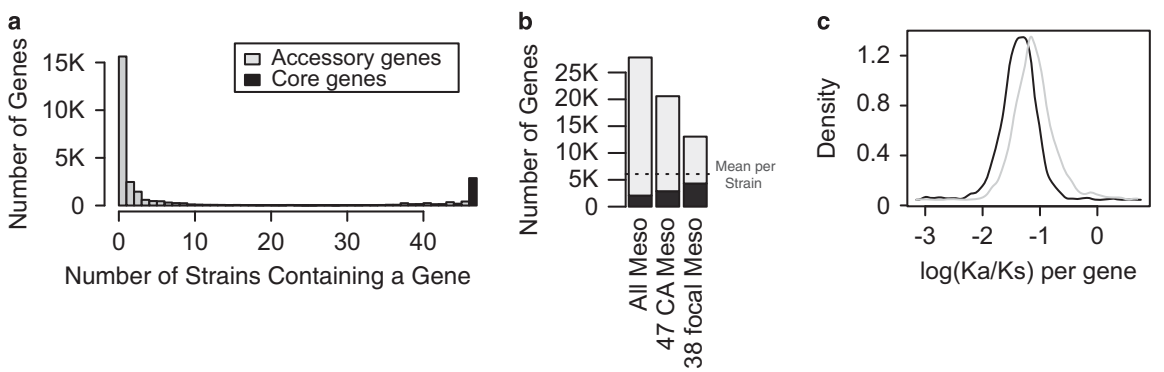

Figure 2 Core and accessory genome compartments of wild Mesorhizobium are distinct. (a) Distribution of genes across strains. (b) Pangenome size for different groups of strains. (c) Distribution of non-synonymous to synonymous substitution ratio (log10 Ka/Ks) for core and accessory genes. 


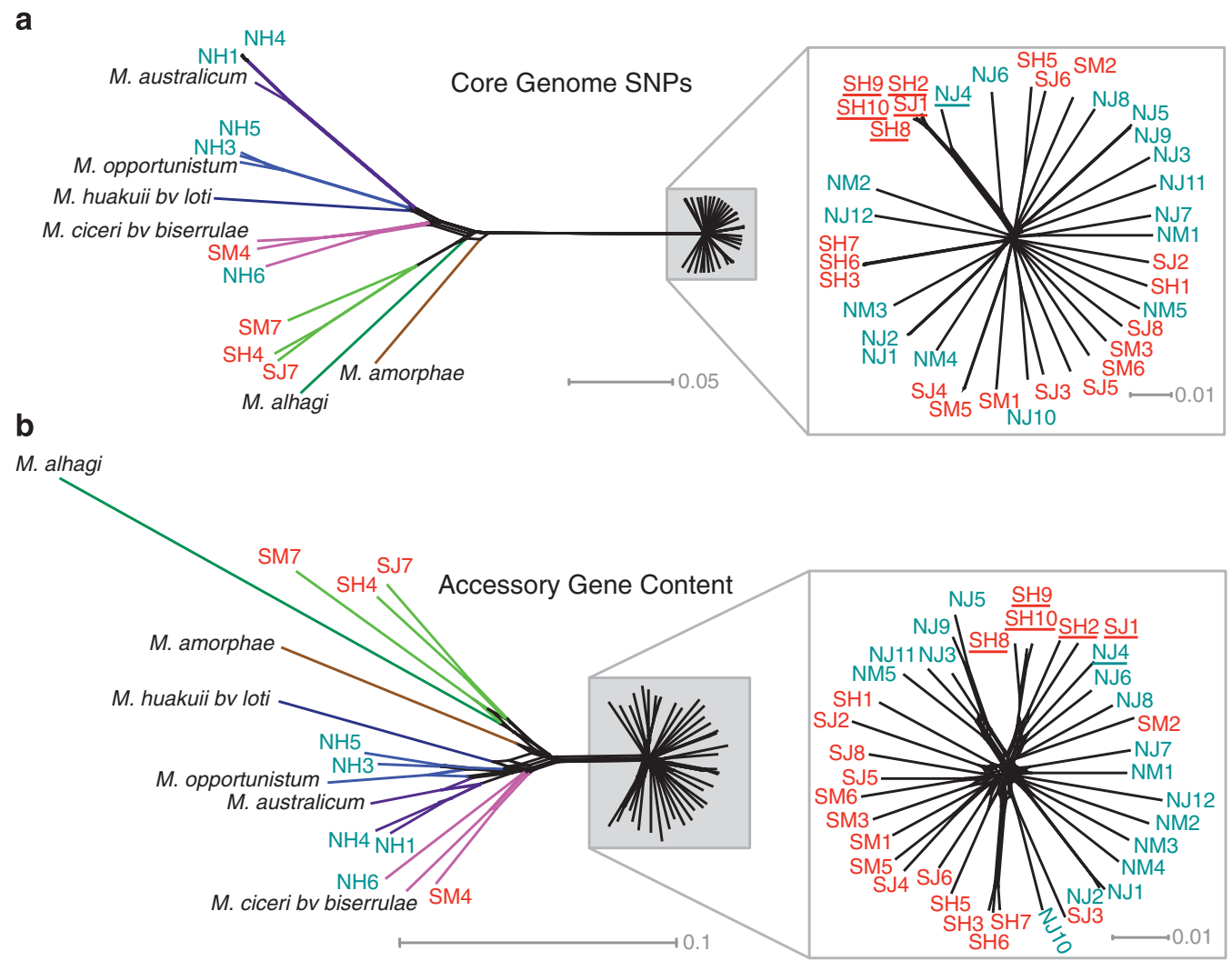

Figure 3 NeighborNet diagrams of strain relatedness indicate the focal clade is genomically cohesive. (a) Relatedness based on SNPs in the core genome; scale bar indicates SNP divergence, scaled by the number of SNPs per bp of aligned core genome. (b) Relatedness based on variation in accessory gene content; scale bar indicates divergence of accessory gene presence/absence. Zoomed region depicts the focal clade (teal: serpentine soil origin; red: non-serpentine soil origin). Strains fully assigned to the minority STRUCTURE subgroup within the focal clade are underlined. Non-focal clades are color-coded for ease of comparison.

the core genome, whereas reserve does not (see 95\% confidence intervals; Supplementary Figure S3).

\section{Adaptive variants}

The presence or absence of 202 accessory genes was associated with a strain's growth phenotype in nickel-enriched media at the 10\% FDR significance level (Figure 4 and Supplementary Table S4; 33 genes significant after Bonferroni correction). In contrast, there were no accessory genes associated with growth in the low-nickel media, even at the $20 \%$ FDR level.

At the stringent Bonferroni-corrected threshold, several nickel-associated accessory genes are predicted to have functional roles in metal tolerance according to homology-based annotation (Table 1, bolded; Table 2). Candidates that share homology with proteins with functional validation in the literature include a putative high-affinity nickel transporter, a chromate ion transporter, a metal cation efflux system protein, a manganese and iron superoxide dismutase protein, and an opine dehydrogenase (Table 2). At 10\% FDR significance, four additional candidate accessory genes have compelling annotations: a cobalt-zinc-cadmium resistance protein, a nickel import ATP-binding protein, an ABC-type dipeptide/oligopeptide/nickel transport system and a nickel-cobalt-cadmium resistance protein (Table 2).

In the core genome, 199 biallelic SNPs associate with growth in nickel-enriched media at 10\% FDR significance (Table 1, Figure 4 and Supplementary Table S5). The single Bonferroni-significant SNP is located in a gene annotated as succinoglycan transport protein exoP (Table 2). No SNP candidates reside in genes homologous to proteins with functions related to nickel.

Candidates from the accessory and core genomes do not fully co-segregate across strains (Figure 5). We identified seven clusters with at least 10 candidate genes, with 3 of these occurring only in serpentineorigin strains. These three clusters span a total of $\sim 131 \mathrm{Kbp}$ and contain 97 of the 202 candidates with 10\% FDR significance. The largest cluster (Cluster A) spans $86 \mathrm{Kbp}$ and contains 77 candidate genes, including 32/33 Bonferroni-significant candidates, all 13 of the candidates that assort perfectly by soil type, and all candidates with supporting evidence for metal tolerance in the literature (Table 2), except for GI:13475426 (Supplementary Table S6). We determined that the 13 candidates that assort perfectly by soil type are within an $\sim 30 \mathrm{Kbp}$ region in Cluster A (Figure 6a). However, their gene order 
a
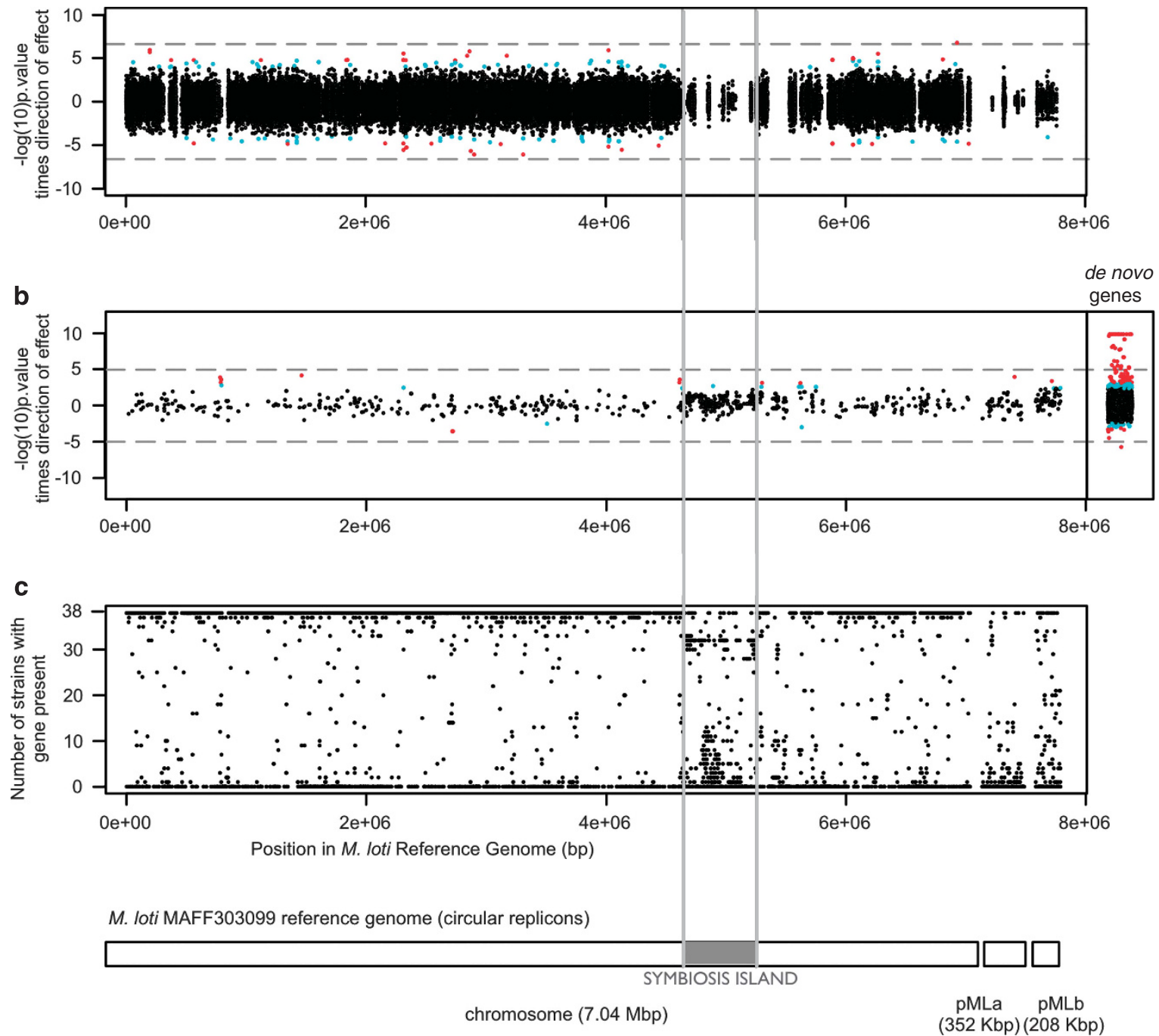

Figure 4 Loci associated with nickel adaptation do not cluster positionally relative to the reference Mesorhizobium huakuii bv. loti genome. Significance of genome-wide association study association of genes with nickel tolerance, corrected for weak genetic structure, in (a) the core genome and (b) the accessory genome (black points: genes not significant; cyan points: $10 \%$ FDR significant; red points: 5\% FDR significant; dashed gray line, Bonferroni significance level; de novo genes are present in the wild strains but absent in the M. huakuii bv. loti reference). (c) Prevalence of each reference M. huakuii bv. loti gene across the wild focal population, shown by the number of wild strains containing each gene (solid gray line: location of the symbiosis island in the reference M. huakuii bv. loti genome). Physical positions of loci in (a-c) correspond to the positions of homologous regions in the M. huakuii bv. loti reference genome diagram; de novo genes in (b) are plotted with jitter because positional information is lacking for them.

and contig position is variable among strains due to non-candidate gene indels, local duplications and transversions (Figure 6a). Two other clusters span a region of $30 \mathrm{Kbp}$ (Cluster $\mathrm{B}$ ) and $15 \mathrm{Kbp}$ (Cluster $\mathrm{C}$ ) and include 10 and 11 candidate genes, respectively (Figures $6 \mathrm{~b}$ and c). Clusters B and C are always found on different contigs, and each is carried by six serpentine strains, with four strains containing both clusters. Clusters B and C have conserved gene content and order, and each contains genes primarily from the de novo assembly, with only one reference gene each; many of the genes in these clusters are annotated as conjugal transfer proteins or transposases (Supplementary Table S6). Groups of reference genes, within and flanking the ends of each cluster, were not consistently co-located in the $M$. huakuii $b v$. loti reference genome. This could be due to structural divergence between the focal population and the reference, or to a complex process of integration of horizontally acquired material into the genome, and precludes the identification of putative cluster insertion sites.

In the focal clade, nickel-adaptation candidates from the accessory genome are shared with lineages that are more phylogenetically distant to the focal clade than expected. This pattern was strongest for nickel-adaptation candidates at 1\% FDR-of these 43 genes, 33 were found in bacterial lineages with existing $16 \mathrm{~S}$ sequence data. On average, this set was $3.3 \%$ more divergent in terms of $16 \mathrm{~S}$ base pair 
Table 1 Candidate genetic variants associated with nickel adaptation include variants functionally implicated in heavy metal tolerance (in bold)

\begin{tabular}{|c|c|c|c|c|c|c|}
\hline \multirow[t]{2}{*}{ Variant } & \multirow[t]{2}{*}{$q$-value } & \multirow{2}{*}{$\begin{array}{c}\text { Ni phenotype } \\
\text { effect }\end{array}$} & \multicolumn{2}{|c|}{ Frequency } & \multirow[t]{2}{*}{ Gene } & \multirow[t]{2}{*}{ Annotation } \\
\hline & & & $S$ & $N$ & & \\
\hline SNP & 0.024 & 0.22 & 1.00 & 0.59 & GI:13476964 & Succinoglycan transport protein exoP (non-synonymous, L/F) \\
\hline \multirow[t]{18}{*}{ Gene } & $5.13 \mathrm{E}-08$ & 0.28 & 1.00 & 0.00 & denovo003242 & CBS domain-containing protein \\
\hline & $5.13 \mathrm{E}-08$ & 0.28 & 1.00 & 0.00 & denovo003246 & Family transcriptional regulator \\
\hline & 5.13E-08 & 0.28 & 1.00 & 0.00 & denovo003256 & Membrane protein \\
\hline & $5.13 \mathrm{E}-08$ & 0.28 & 1.00 & 0.00 & denovo003257 & Major facilitator transporter; $\mathrm{H}+$ antiporter protein \\
\hline & $5.13 \mathrm{E}-08$ & 0.28 & 1.00 & 0.00 & denovo003258 & Cation diffusion facilitator family transporter \\
\hline & 5.13E-08 & 0.28 & 1.00 & 0.00 & denovo003265 & Opine dehydrogenase \\
\hline & $5.13 \mathrm{E}-08$ & 0.28 & 1.00 & 0.00 & denovo003268 & Peroxidase-related enzyme \\
\hline & 5.13E-08 & 0.28 & 1.00 & 0.00 & denovo003270 & ABC-type polar amino acid transport ATPase component \\
\hline & $5.13 \mathrm{E}-08$ & 0.28 & 1.00 & 0.00 & denovo003273 & Amino acid ABC permease 3-tm his glu gln arg opine family \\
\hline & 8.17E-08 & 0.28 & 0.95 & 0.00 & denovo003272 & Amino acid ABC permease 3-tm his glu gln arg opine family \\
\hline & $2.14 \mathrm{E}-07$ & 0.27 & 0.95 & 0.00 & denovo003267 & Flavoprotein involved in $\mathrm{K}+$ transport \\
\hline & 4.32E-06 & 0.26 & 0.81 & 0.00 & denovo003240 & Recombinase \\
\hline & $1.38 \mathrm{E}-04$ & 0.24 & 0.86 & 0.00 & denovo003271 & $\begin{array}{l}\text { Periplasmic component of AA-type transporter signal transduction } \\
\text { system }\end{array}$ \\
\hline & $1.58 \mathrm{E}-04$ & 0.24 & 0.90 & 0.00 & denovo003269 & ABC-type polar amino acid transport ATPase component \\
\hline & $4.50 \mathrm{E}-04$ & 0.22 & 0.95 & 0.41 & denovo000014 & High-affinity nickel-transporter \\
\hline & $5.85 \mathrm{E}-04$ & 0.23 & 0.81 & 0.00 & denovo003250 & Manganese and iron superoxide dismutase \\
\hline & 7.96E-04 & 0.24 & 0.62 & 0.00 & denovo003455 & $\begin{array}{l}\text { Aminophosphonate oxidoreductase; hydrolase; FAD dependent } \\
\text { oxidoreductase }\end{array}$ \\
\hline & $9.69 \mathrm{E}-04$ & 0.22 & 0.76 & 0.00 & denovo003248 & Chromate ion transporter family \\
\hline
\end{tabular}

The $q$-values indicate significance values for loci in an FDR-controlled association test on residual trait values corrected for weak genetic structure. Values remain significant after Bonferroni correction. Fifteen unannotated candidates are omitted. Positive Ni phenotype effect ${ }^{\mathrm{a}}$ values indicate that a variant is associated with nickel tolerance rather than sensitivity. Frequency of the variant is given for strains from serpentine (S) and nonserpentine $(\mathrm{N})$ soils. Annotations are based upon Blast2Go. Polymorphism type is parenthetically indicated for the SNP candidate.

${ }^{a} \mathrm{Ni}$ phenotype effect is the mean growth (OD600) in Ni-enriched media of strains with the reference variant minus that of strains lacking the variant.

similarity (0.033 average nucleotide identity) from M. huakuii bv. loti than lineages sharing the closest homologs to non-candidate accessory genes (Wilcoxon test $P=0.023$; Figure 5c). This result also held for the 5\% FDR set of genes (62/87 genes with $16 \mathrm{~S}$ distance, Wilcoxon difference $0.006, P=0.034$ ) and the pattern was marginally significant for the FDR $10 \%$ genes $(128 / 202$ genes with $16 \mathrm{~S}$ distance, Wilcoxon difference 0.0029, $P=0.076$ ).

\section{Discussion}

Understanding rhizobial adaptation to soil environments is important because symbiotic rhizobia are responsible for half of all current biologically fixed nitrogen (Gruber and Galloway, 2008) yet live the majority of their lives in soil. Genomic analysis of a population of wild Mesorhizobium from California shows that adaptive differentiation across contrasting soil nickel levels occurs within an otherwise cohesive genome and gives insight into the biogeography of the pan-genome, the identity of adaptive genomic variants and the process of environmental adaptation in bacteria.

Genomic context of environmental adaptation

The focal Mesorhizobium clade in this study is a genomically cohesive population that is widely dispersed across habitat boundaries yet harbors ecotypic variation for adaptation to high-nickel soils. Phylogenomic analysis of this population (99.8\% 16S similarity) yields a star-like topology for both variation in the core and accessory genomes, with relatively long terminal branches that reflect strainspecific mutations similar to those observed in other rhizobial populations (Bailly et al., 2011; Kumar et al., 2015). STRUCTURE analysis further supports this population's distinctness from other sympatric strains. The lack of phylogenetic structure within the focal population is consistent with recombination homogenizing the core and accessory genomes among soil types and across hundreds of kilometers. A similar pangenomic pattern was observed in early stages of habitat-based ecotypic differentiation in a wild population of marine Vibrio cyclitrophicus (Shapiro et al., 2012), and Ensifer meliloti rhizobia display similar homogenizing levels of recombination across host species and thousands of kilometers (Epstein et al., 2012).

Bacterial pan-genomes typically consist of distinct core and accessory genome compartments and our Mesorhizobium draft genome sequences recapitulate this pattern. Our assemblies appear to capture the vast majority of genomic content despite not being fully closed, because they are similar in size to related closed genomes and a high fraction of raw reads are used in the assembly (95-98\%). 


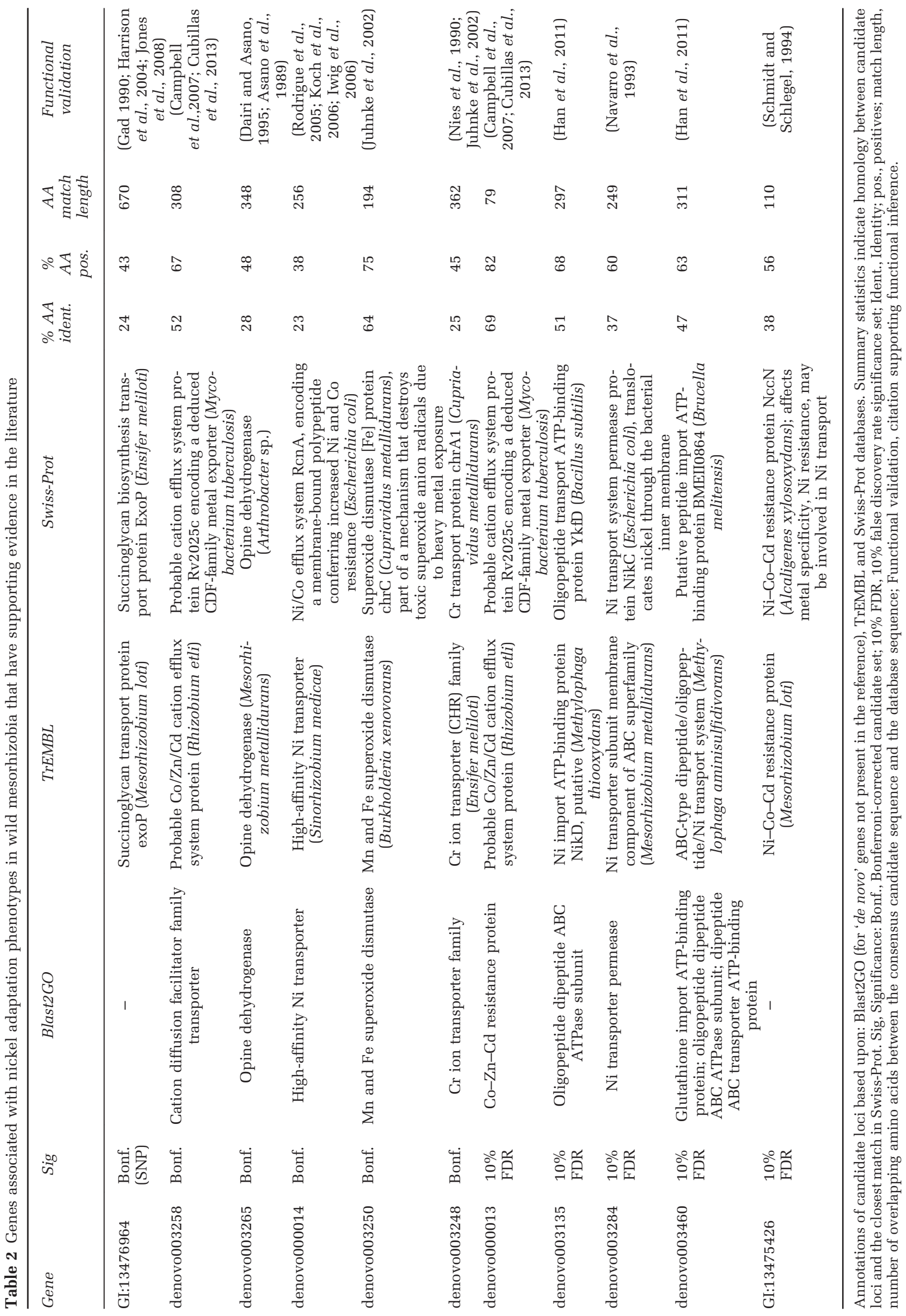


a

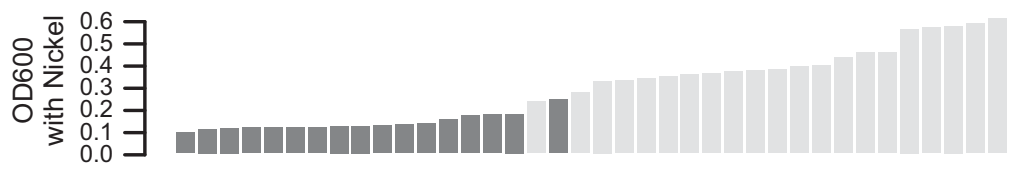

b
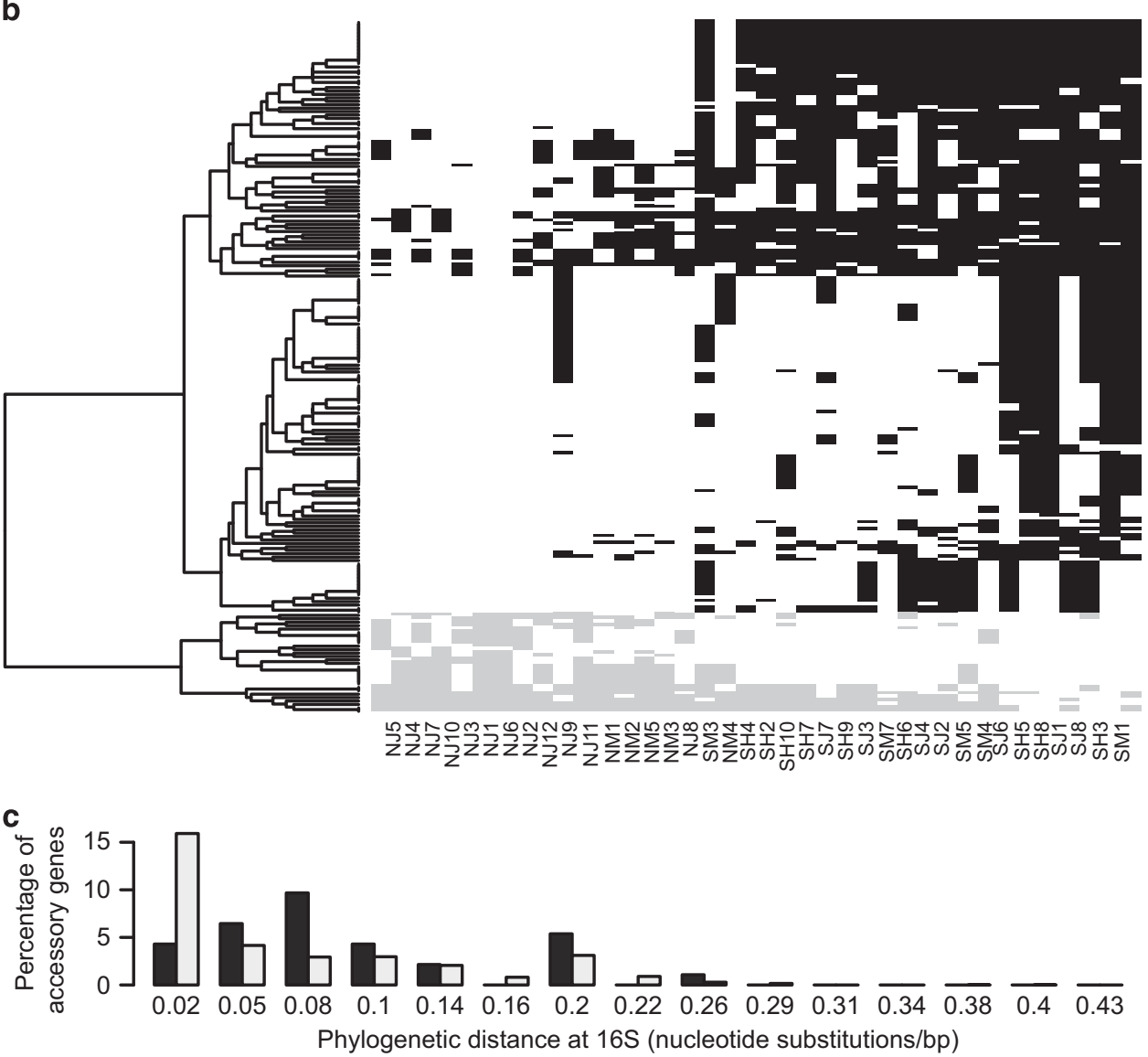

Figure 5 Candidate loci from the accessory genome do not strictly co-segregate and tend to be shared with lineages that are relatively distantly related to Mesorhizobium. (a) Growth of each focal population strain in media containing 1 mm nickel (dark gray: non-serpentine origin; light gray: serpentine origin). Strain identity is indicated in corresponding column of (b). (b) Pattern of co-segregation of accessory gene nickel adaptation candidates (10\% FDR set) across the 38 strains in the focal population (black: candidates associated with increased growth in nickel; gray: candidates associated with decreased growth in nickel). Genes are ordered based on co-segregation as indicated in the dendrogram. (c) Phylogenetic distance at $16 \mathrm{~S}$ between focal clade mesorhizobia and the bacterial lineage with the closest homolog to each accessory gene (dark gray: FDR 1\% accessory gene candidates; light gray: all accessory genes with a match for which we could extract $16 \mathrm{~S}$ information).

Contrasting patterns of functional enrichment and molecular evolution in core vs accessory Mesorhizobium genomic compartments demonstrate that they experience different evolutionary processes. The accessory genome is strongly enriched in genes related to DNA recombination and metabolism, and many appear to reside in the symbiosis island region. These characteristics accord with the concept that horizontally transferred genes occur at sites of recombination (Karberg et al., 2011) and that intrapopulation gene content variation results largely from phage, plasmid and transposon movement (Denef et al., 2010b). The accessory genome is also enriched for cell membrane cellular compartment GO terms, similar to findings from studies of biotic drivers of rapidly evolving cell-surface molecules, membrane-spanning transporters and cell membrane modifiers, which play key roles in microbial biotic interactions (Kettler et al., 2007; Cordero et al., 2012a; Polz et al., 2013). Biotic selection, environmental selection, or mutational bias could underlie the elevated rates of protein sequence evolution relative to genome sequence change that we observe in the accessory genome; although most core and accessory genomes have a negative log ratio of nonsynonymous to synonymous substitution which suggests primarily purifying selection, as observed in Ensifer rhizobia (Epstein et al., 2014). Higher network reticulation for the accessory genome compared with the core genome is consistent with a pattern of horizontal exchange of accessory genes among lineages (Polz et al., 2013). However, at 
a

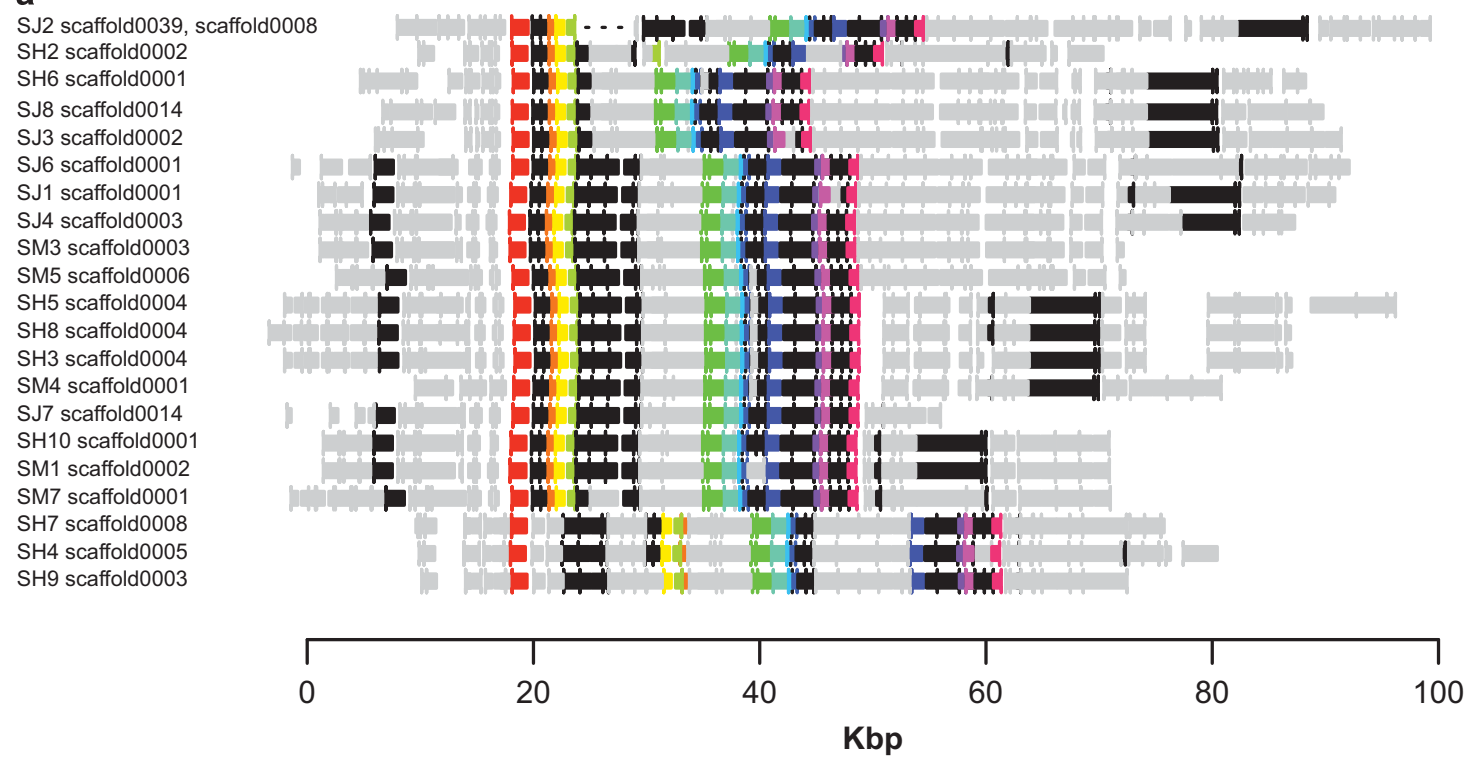

b
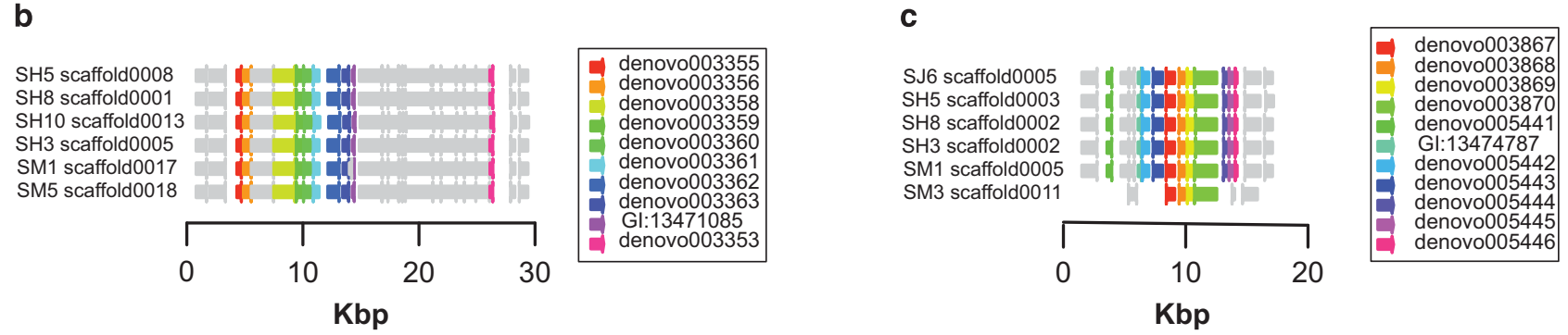

Figure 6 Clusters of candidate nickel adaptation genes. (a) Cluster A, found in all serpentine-origin strains, contains 32 Bonferronisignificant genes (black), 13 of which are only found in serpentine strains (rainbow). Other genes are gray. (b) Cluster B contains 10 genes significant at FDR 10\% (rainbow); other genes in gray. (c) Cluster C contains 11 genes significant at FDR 10\% (rainbow); other genes in gray. Flat arrowheads denote the $3^{\prime}$ end of genes.

broader phylogenetic scales these Mesorhizobium core and accessory genomes yield congruent topologies, in contrast to the divergent phylogenetic processes acting at core and accessory genomic compartments in Rhizobium leguminosarum (Kumar et al., 2015).

Bacterial populations are often weakly structured by geographic distance, particularly in taxa that can disperse via aerial dust or surface water (Martiny et al., 2006; Hanson et al., 2012). We find that both geographic location and soil type explain low but significant amounts of genomic variation within our focal population. Environmental selection appears to be stronger and play a relatively large role in structuring accessory genes compared with core genes, as accessory genes showed greater divergence across soil types than core genes, but equivalent isolation by distance. Given that only a few migrants per generation are sufficient for complete population admixture, our observation of genetic structure across adjacent serpentine and non-serpentine soils points to strong environmental selection, particularly since gene flow, in the present study and other studies, commonly occurs over geographic distances several orders of magnitude higher (Shapiro and Polz, 2014). Our study adds to a growing list of microbial populations that remain cohesive at neutral loci despite large-scale geographic separation (Shapiro and Polz, 2014).

Genetic variants underlying environmental adaptation As phylogenetic and biogeographic evidence indicate that our focal Mesorhizobium population experiences ongoing recombination, we undertook a genome-wide association study to detect genetic variants associated with nickel adaptation (Friesen and von Wettberg, 2010; Chen and Shapiro, 2015). The majority of candidate variants for nickel adaptation are gene content variants in the accessory genome rather than allelic variants in the core genome. Numerous candidate genes have high statistical support and homology to loci that have been experimentally demonstrated to be involved in nickel tolerance, consistent with the perspective that the accessory genome is a reservoir of adaptive genes (Coleman and Chisholm, 2010; Polz et al., 2013), though there could be rare genes associated with 
nickel tolerance we are unable to detect with genome-wide association study.

Nickel efflux systems prevent toxic intracellular nickel concentrations (Macomber and Hausinger, 2011) and are upregulated in response to metal exposure in other mesorhizobia (Maynaud et al., 2013). We find several candidate loci with putative roles in the transport of nickel or other divalent cations-common resistance proteins often underlie adaptation to multiple divalent cations (Macomber and Hausinger, 2011). Candidate 'denovo000014' is homologous to a high-affinity nickel transporter in Ensifer medicae and the nickel/cobalt efflux system RcnA. RcnA is a membrane-bound polypeptide that contributes to nickel resistance (Rodrigue et al., 2005; Koch et al., 2006; Iwig et al., 2006) and nickel homeostasis (Macomber and Hausinger, 2011). Candidate 'denovo003248' shares homology with a putative chromate transport protein in E. meliloti and chromate transport protein chrA1, a plasmidborne gene that contributes to chromate efflux in metal-tolerant Cupriavidus metallidurans (Nies et al., 1990; Juhnke et al., 2002). Elevated soil chromate may be associated with elevated soil nickel concentrations (Brady et al., 2005), or this transporter could recognize a negatively charged nickel complex. Candidates 'denovo003258' and 'denovo000013' are related genes that share homology with a probable cobalt-zinc-cadmium efflux system protein in Rhzobium etli, as well as cation efflux protein Rv2025c, which encodes a functionally validated cation diffusion facilitator (CDF)family metal exporter in Mycobacterium tuberculosis (Campbell et al., 2007). Rv2025c is de-repressed by $\mathrm{Ni}^{2+}$ and $\mathrm{Co}^{2+}$, is controlled by the high-affinity $\mathrm{Ni}^{2+} / \mathrm{Co}^{2+}$ sensor $\mathrm{KmtR}$ and may use $\mathrm{Ni}^{2+}$ as a substrate (Cubillas et al., 2013). Candidate 'denovo003460' has homology to an inferred ABCtype dipeptide/oligopeptide/nickel transport system in Methylophaga aminisulfidivorans (Han et al., 2011). Accessory gene candidate 'GI:13475426' is annotated as a nickel-cobalt-cadmium resistance protein in Mesorhizobium huakuii bv. loti and is homologous to NccN, a nickel-cadmium-cobalt resistance protein that contributes to nickel efflux in Alcaligenes xylosoxydans (Schmidt and Schlegel, 1994). Genes in the ncc operon share close homology with those in the cnr operon, a cobalt nickel efflux system integral to nickel tolerance in Bradyrhizobium from serpentine soil (Chaintreuil et al., 2007). Candidate 'denovo003135'is homologous to a putative nickel import ATP-binding protein, NikD, in Methlyophaga thiooxydans DMS010 (Han et al., 2011).

Three other candidates are annotated with functions that suggest involvement in symbiosis and/or environmental stress. Candidate 'denovo003250' is homologous to iron superoxide dismutase protein ChrC, which contributes to nickel tolerance in C. metallidurans (Juhnke et al., 2002). Superoxide dismutase scavenges superoxides produced during oxidative damage and also confers nickel tolerance in Escherichia coli (Macomber and Hausinger, 2011). Candidate 'denovo003265' is annotated as an opine dehydrogenase (Asano et al., 1989; Dairi and Asano, 1995). Opines, specialized bacterial metabolites produced during symbiosis, have roles in host colonization and communication (Denison, 2000; Savka et al., 2002). As heavy metals can inhibit symbiosis initiation (Mengoni et al., 2010), opines might play a role in symbiotic adaptation to serpentine soils. Finally, we find a well-supported candidate SNP in the succinoglycan transport protein ExoP. The extracellular polysaccharide succinoglycan is involved in symbiosis (Jones et al., 2008) and can also mediate biofilm formation, which could contribute to nickel tolerance (Harrison et al., 2004); extracellular polysaccharide molecules may also bind metal directly and contribute to tolerance (Gadd, 1990).

The evolutionary processes underlying environmental adaptation

The focal Mesorhizobium population exhibits environment-specific adaptive variants, yet lacks strong genome-wide differentiation between environments, suggesting that gene flow across environments may maintain genomic cohesion within this population. This is consistent with a population classification of 'stage 2' in Shapiro and Polz's (2014) continuous speciation spectrum model. The best supported adaptive variants are clustered positionally within a $30 \mathrm{Kbp}$ stretch in the Cluster A region in the genomes of all serpentineorigin strains. The $\sim 86 \mathrm{Kbp}$ Cluster A region contains 32/33 Bonferroni-supported candidates, fully assorts with serpentine soil and contains nearly all of the candidates with annotations that suggest a role in nickel adaptation. However, there is evidence that two additional clusters of candidates supported at the $10 \%$ FDR level occur in subsets of the most nickel-tolerant strains, and 105 of the 202 candidate loci supported at the 10\% FDR level are not clustered by our metric. The fact that serpentine-origin strains harbor at least one wellsupported cluster of adaptive variants within a pan-genome otherwise mixed with non-serpentine strains by migration and recombination is consistent with at least one gene-specific sweep leading to the prevalence of candidates in Cluster $A$ in nickel-adapted strains (Shapiro and Polz, 2014). Our data also suggest that multiple adaptive regions could act independently to confer nickel tolerance, which could further support additional genespecific sweeps, though annotation-based support for these regions' involvement in nickel adaptation is less strong. Alternatively, historical genomewide sweeps (clonal sweeps) could occur via strong selection in serpentine soils for adaptive variants in the absence of recombination. The resulting widespread clonal genotype could subsequently 
diversify by neutral processes, leaving locally adaptive regions under continued selection as remnants of ancient clonal divergence (Shapiro and Polz, 2014). These alternatives could be tested by assessing the relative pattern of polymorphism in candidate regions, and the level of synonymous divergence between habitats would shed light on which scenario is more likely (Shapiro and Polz, 2014).

Our findings support previous work showing that the accessory genome acts as a reservoir that harbors adaptive variation resulting from selection that impacts microbial populations at local ecological scales (Coleman and Chisholm, 2010; Doolittle and Zhaxybayeva, 2010; Polz et al., 2013; Cordero and Polz, 2014). While many of the candidates we identify may be simply linked to adaptive variants, the functional annotation of numerous candidates suggests roles in nickel tolerance. Horizontal gene transfer, by which lineages can acquire genetic material from distantly related lineages, is one process structuring accessory genome content (Polz et al., 2013). Typically, rates of horizontal gene transfer and recombination decline rapidly with sequence divergence between strains of bacteria (Polz et al., 2013), negative epistatic interactions increase with divergence between source lineages (Polz et al., 2013), and most horizontally transferred genes in rhizobia appear to be somewhat deleterious (Epstein et al., 2014) and subject to strong purifying selection (Epstein et al., 2014). However, our findings are consistent with a pattern by which selection maintains horizontally acquired genes shared with phylogenetically distant lineages. Strong, environmentally dependent selection on nickel tolerance could result in an excess of nickel-adaptive loci from distant lineages. Future closed genome sequencing would enable us to locate candidates within the replicon structure, as heavy metal tolerance in rhizobia can be conferred by plasmids (Lakzian et al., 2002, 2007).

Our focal population shows adaptation to highnickel serpentine soil, but does not show the pattern of reciprocal local adaptation found in the larger set of 292 Mesorhizobium strains (Porter and Rice, 2013). In the larger set, strains from high-nickel serpentine soil outperformed those from low-nickel non-serpentine soil in high-nickel media, and non-serpentine strains outperformed serpentine strains in low-nickel media. However, in the subset of strains in the focal population, nonserpentine ecotypes have no fitness advantage over serpentine ecotypes in the absence of nickel. This generalist population may have escaped the cost to metal tolerance observed in the larger, more phylogenetically diverse set of randomly selected environmental mesorhizobia (Porter and Rice, 2013), which could be due to migration alleviating the accumulation of environment-specific deleterious mutations (Kawecki, 1994) and could simultaneously be key to ongoing gene flow that prevents reproductive isolation across soil type boundaries (Shapiro and Polz, 2014). This lack of nonserpentine strain fitness advantage could have alternative explanations, such as a maladaptation load in non-serpentine strains due to recombination with serpentine strains. Future work could use a phylogentically controlled method to investigate how such trade-offs could result in varying patterns of gene flow to influence patterns of diversity (Gudelj et al., 2010).

\section{Conclusion}

We observe habitat specialization within an otherwise genomically cohesive population of wild mesorhizobia, rather than finding distinct, specialized bacterial lineages in contrasting soil types. Thus, heterogeneous environments can drive selection maintaining adaptive variants at a small fraction of the genome. Our work proposes candidate genes for nickel adaptation, several of which show homology to already-characterized genetic systems for nickel tolerance, which validates the general approach of ascribing habitat-assorting genomic variation to the processes of ecotypic adaptation.

\section{Conflict of Interest}

The authors declare no conflict of interest.

\section{Acknowledgements}

This work was funded by an NSF DDIG DEB-0909154 to SSP, NSF DEB-0820846 to SN, NSF DEB-1354878 to MLF and NSF DEB-1355216 to SSP. We thank D Cook, J Eisen and $\mathrm{P}$ Taylor and three anonymous reviewers for helpful comments. We thank the Jasper Ridge Biological Preserve, the Donald and Sylvia McLaughlin Natural Reserve, and the Hopland Research and Extension Center for access to field sites.

\section{Data deposition}

All sequence data are available under the NCBI BioProject PRJNA171524. The Whole Genome Shotgun sequences have been deposited at DDBJ/EMBL/ GenBank under the accessions AYVK00000000AYXF00000000, http://www.ncbi.nlm.nih.gov/bioproject $/$ ?term $=$ PRJNA171524.

\section{Author contributions}

SSP and MLF designed research; SSP, PLC, CAC, JPD and MLF performed research and analyzed data, and SSP and MLF wrote the paper. 


\section{References}

Andam CP, Gogarten JP. (2011). Biased gene transfer in microbial evolution. Nat Rev Microbiol 9: 543-555.

Asano Y, Yamaguchi K, Kondo K. (1989). A New Nad +-dependent opine dehydrogenase from Arthrobacter sp strain-1c. J Bacteriol 171: 4466-4471.

Bailly X, Giuntini E, Sexton MC, Lower RP, Harrison PW, Kumar N et al. (2011). Population genomics of Sinorhizobium medicae based on low-coverage sequencing of sympatric isolates. ISME J 5: 1722-1734.

Boucher Y, Cordero OX, Takemura A, Hunt DE, Schliep K, Bapteste E et al. (2011). Local mobile gene pools rapidly cross species boundaries to create endemicity within global Vibrio cholerae populations. mBio 2: e00335-10-e00335-10.

Brady KU, Kruckeberg AR, Bradshaw HD. (2005). Evolutionary ecology of plant adaptation to serpentine soils. Annu Rev Ecol Evol Syst 36: 243-266.

Campbell DR, Chapman KE, Waldron KJ, Tottey S, Kendall S, Cavallaro $G$ et al. (2007). Mycobacterial cells have dual nickel-cobalt sensors: sequence relationships and metal sites of meta-repsponsive repressors are not congruent. J Biol Chem 282: 32298-32310.

Chaintreuil C, Rigault F, Moulin L, Jaffre T, Fardoux J, Giraud E et al. (2007). Nickel resistance determinants in Bradyrhizobium strains from nodules of the endemic New Caledonia legume Serianthes calycina. Appl Environ Microbiol 73: 8018-8022.

Chen PE, Shapiro BJ. (2015). The advent of genome-wide association studies for bacteria. Curr Opin Microbiol 25: $17-24$.

Cohan FM. (2002). What are bacterial species? Annu Rev Microbiol 56: 457-487.

Cohan FM, Perry EB. (2007). A systematics for discovering the fundamental units of bacterial diversity. Curr Biol 17: R373-R386.

Coleman ML, Chisholm SW. (2010). Ecosystem-specific selection pressures revealed through comparative population genomics. Proc Natl Acad Sci 107: 18634-18639.

Conesa A, Gotz S, Garcia-Gomez JM, Terol J, Talon M, Robles M. (2005). Blast2GO: a universal tool for annotation, visualization and analysis in functional genomics research. Bioinformatics 21: 3674-3676.

Cordero OX, Polz MF. (2014). Explaining microbial genomic diversity in light of evolutionary ecology. Nat Rev Microbiol 12: 263-273.

Cordero OX, Ventouras L-A, DeLong EF, Polz MF. (2012a). Public good dynamics drive evolution of iron acquisition strategies in natural bacterioplankton populations. Proc Natl Acad Sci 109: 20059-20064.

Cordero OX, Wildschutte H, Kirkup B, Proehl S, Ngo L, Hussain $\mathrm{F}$ et al. (2012b). Ecological populations of bacteria act as socially cohesive units of antibiotic production and resistance. Science 337: 1228-1231.

Cubillas C, Vinuesa P, Tabche ML, Santos AG-DL. (2013). Phylogenomic analysis of cation diffusion facilitator proteins uncovers Ni 2+/Co 2+ transporters. Metallomics 5: 1634-1643.

Dairi T, Asano Y. (1995). Cloning, nucleotide sequencing, and expression of an opine dehydrogenase gene from Arthrobacter sp strain 1c. Appl Environ Microbiol 61: 3169-3171.

Denef VJ, Kalnejais LH, Mueller RS, Wilmes P, Baker BJ, Thomas BC et al. (2010a). Proteogenomic basis for ecological divergence of closely related bacteria in natural acidophilic microbial communities. Proc Natl Acad Sci USA 107: 2383-2390.

Denef VJ, Mueller RS, Banfield JF. (2010b). AMD biofilms: using model communities to study microbial evolution and ecological complexity in nature. ISME $J \mathbf{4}$ : 599-610.

Denison RF. (2000). Legume sanctions and the evolution of symbiotic cooperation by rhizobia. Am Nat 156: $567-576$.

Dixon P. (2003). VEGAN, a package of $\mathrm{R}$ functions for community ecology. J Veg Sci 14: 927-930.

Doolittle WF, Zhaxybayeva O. (2010). Metagenomics and the units of biological organization. Bioscience 60: 102-112.

Dunham JP, Friesen ML. (2013). A cost-effective method for high-throughput construction of Illumina sequencing libraries. Cold Spring Harbor Protocols 2013: 820-834.

Ellison CE, Hall C, Kowbel D, Welch J, Brem RB, Glass NL et al. (2011). Population genomics and local adaptation in wild isolates of a model microbial eukaryote. Proc Natl Acad Sci 108: 2831-2836.

Epstein B, Branca A, Mudge J, Bharti AK, Briskine R, Farmer AD et al. (2012). Population genomics of the facultatively mutualistic bacteria Sinorhizobium meliloti and S. medicae. PLOS Genet 8: e1002868.

Epstein B, Sadowsky MJ, Tiffin P. (2014). Selection on horizontally transferred and duplicated genes in sinorhizobium (ensifer), the root-nodule symbionts of medicago. Genome Biol Evol 6: 1199-1209.

Evanno G, Regnaut S, Goudet J. (2005). Detecting the number of clusters of individuals using the software STRUCTURE: a simulation study. Mol Ecol 14: 2611-2620.

Falcon S, Gentleman R. (2007). Using GOstats to test gene lists for GO term association. Bioinformatics 23: 257-258.

Friesen ML, von Wettberg EJ. (2010). Adapting genomics to study the evolution and ecology of agricultural systems. Curr Opin Plant Biol 13: 119-125.

Gadd GM. (1990). Heavy metal accumulation by bacteria and other microorganisms. Experientia 46: 834-840.

Gevers D, Cohan FM, Lawrence JG, Spratt BG, Coenye T, Feil EJ et al. (2005). Opinion: re-evaluating prokaryotic species. Nat Rev Microbiol 3: 733-739.

Giller KE, Witter E, McGrath SP. (2009). Heavy metals and soil microbes. Soil Biol Biochem 41: 2031-2037.

Gruber N, Galloway JN. (2008). An Earth-system perspective of the global nitrogen cycle. Nature 451: 293-296.

Gudelj I, Weitz JS, Ferenci T, Horner-Devine MC, Marx CJ, Meyer JR et al. (2010). An integrative approach to understanding microbial diversity: from intracellular mechanisms to community structure. Ecol Lett 13: 1073-1084.

Han GH, Kim W, Chun J, Kim SW. (2011). Draft genome sequence of Methylophaga aminisulfidivorans MPT. J Bacteriol 193: 4265-4265.

Hanson CA, Fuhrman JA, Horner-Devine MC, Martiny JBH. (2012). Beyond biogeographic patterns: processes shaping the microbial landscape. Nat Rev Microbiol 10: $497-506$.

Harrison JJ, Ceri H, Stremick CA, Turner RJ. (2004). Biofilm susceptibility to metal toxicity. Environ Microbiol 6: 1220-1227.

Hochberg Y, Benjamini Y. (1990). More powerful procedures for multiple significance testing. Stat Med 9: 811-818. 
Huson DH. (2005). Application of phylogenetic networks in evolutionary studies. Mol Biol Evol 23: 254-267.

Huson DH. (1998). SplitsTree: analyzing and visualizing evolutionary data. Bioinformatics 14: 68-73.

Iwig JS, Rowe JL, Chivers PT. (2006). Nickel homeostasis in Escherichia coli-the rcnR-rcnA efflux pathway and its linkage to NikR function. Mol Microbiol 62: 252-262.

Jones KM, Sharopova N, Lohar DP, Zhang JQ, VandenBosch KA, Walker GC. (2008). Differential response of the plant Medicago truncatula to its symbiont Sinorhizobium meliloti or an exopolysaccharidedeficient mutant. Proc Natl Acad Sci 105: 704-709.

Juhnke S, Peitzsch N, Hübener N, Große C, Nies DH. (2002). New genes involved in chromate resistance in Ralstonia metallidurans strain CH34. Arch Microbiol 179: $15-25$.

Karberg KA, Olsen GJ, Davis JJ. (2011). Similarity of genes horizontally acquired by Escherichia coli and Salmonella enterica is evidence of a supraspecies pangenome. Proc Nat Acad Sci 108: 20154-20159.

Kawecki TJ. (1994). Accumulation of deleterious mutations and the evolutionary cost of being a generalist. Am Nat 144: 833-838.

Kettler GC, Martiny AC, Huang K, Zucker J, Coleman ML, Rodrigue S et al. (2007). Patterns and implications of gene gain and loss in the evolution of Prochlorococcus. PLoS Genet 3: 2515-2528.

Koch D, Nies DH, Grass G. (2006). The RcnRA (YohLM) system of Escherichia coli: A connection between nickel, cobalt and iron homeostasis. Biometals 20: 759-771.

Konstantinidis KT, Tiedje JM. (2005). Genomic insights that advance the species definition for prokaryotes. Proc Natl Acad Sci USA 102: 2567-2572.

Kumar N, Lad G, Giuntini E, Kaye ME, Udomwong P, Shamsani NJ et al. (2015). Bacterial genospecies that are not ecologically coherent: population genomics of Rhizobium leguminosarum. Open Biol 5: 140133-140133.

Kuo CH, Ochman H. (2009). The fate of new bacterial genes. Fems Microbiol Rev 33: 38-43.

Lakzian A, Murphy P, Giller KE. (2007). Transfer and loss of naturally occurring plasmids among isolates of Rhizobium leguminosarum bv. viciae in heavy metal contaminated soils. Soil Biol Biochem 39: 1066-1077.

Lakzian A, Murphy P, Turner A, Beynon JL, Giller KE. (2002). Rhizobium leguminosarum bv. viciae populations in soils with increasing heavy metal contamination: abundance, plasmid profiles, diversity and metal tolerance. Soil Biol Biochem 34: 519-529.

Lapierre P, Gogarten JP. (2009). Estimating the size of the bacterial pan-genome. Trends Genet 25: 107-110.

Larkin MA, Blackshields G, Brown NP, Chenna R, McGettigan PA, McWilliam H et al. (2007). Clustal W and clustal $\mathrm{X}$ version 2.0. Bioinformatics 23: 2947-2948.

Macomber L, Hausinger RP. (2011). Mechanisms of nickel toxicity in microorganisms. Metallomics 3: 1153-1162.

Martiny JBH, Bohannan BJM, Brown JH, Colwell RK, Fuhrman JA, Green JL et al. (2006). Microbial biogeography: putting microorganisms on the map. Nat Rev Microbiol 4: 102-112.

Maynaud G, Brunel B, Mornico D, Durot M, Severac D, Dubois E et al. (2013). Genome-wide transcriptional responses of two metal-tolerant symbiotic Mesorhizobium isolates to zinc and cadmium exposure. BMC Genomics 14: 292.
McNeilly T. (1968). Evolution in closely adjacent plant populations 3: Agrostis tenuison on a small copper mine. Heredity 23: 99.

Mengoni A, Schat H, Vangronsveld J. (2010). Plants as extreme environments? Ni-resistant bacteria and Nihyperaccumulators of serpentine flora. Plant Soil 331: 5-16.

Navarro C, Wu LF, Mandrand-Berthelot MA. (1993). The nik operon of Escherichia coli encodes a periplasmic binding-protein-dependent transport system for nickel. Mol Microbiol 9: 1181-1191.

Nies A, Nies DH, Silver S. (1990). Nucleotide sequence and expression of a plasmid-encoded chromate resistance determinant from Alcaligenes eutrophus. J Biol Chem 265: 5648-5653.

Oldroyd GED, Harrison MJ, Paszkowski U. (2009). Reprogramming plant cells for endosymbiosis. Science 324: $753-754$.

Polz MF, Alm EJ, Hanage WP. (2013). Horizontal gene transfer and the evolution of bacterial and archaeal population structure. Trends Genet 29: 170-175.

Porter SS, Rice KJ. (2013). Trade-offs, spatial heterogeneity, and the maintenance of microbial diversity. Evolution 67: 599-608.

Pritchard JK, Stephens M, Donnelly P. (2000). Inference of population structure using multilocus genotype data. Genetics 155: 945-959.

Reno ML, Held NL, Fields CJ, Burke PV, Whitaker RJ. (2009). Biogeography of the Sulfolobus islandicus pan-genome. Proc Natl Acad Sci 106: 8605-8610.

Rodrigue A, Effantin G, Mandrand-Berthelot MA. (2005). Identification of rcnA (yohM), a nickel and cobalt resistance gene in Escherichia coli. J Bacteriol 187: 2912-2916.

Rosen MJ, Davison M, Bhaya D, Fisher DS. (2015). Finescale diversity and extensive recombination in a quasisexual bacterial population occupying a broad niche. Science 348: 1019-1023.

Sa-Pereira P, Rodrigues M, Simoes F, Domingues L, Castro IVE. (2009). Bacterial activity in heavy metals polluted soils: metal efflux systems in native rhizobial strains. Geomicrobiol J 26: 281-288.

Savka MA, Dessaux Y, Oger P, Rossbach S. (2002). Engineering bacterial competitiveness and persistence in the phytosphere. Mol Plant Microbe Interact 15: 866-874.

Schmidt T, Schlegel HG. (1994). Combined nickel-cobaltcadmium resistance encoded by the ncc locus of Alcaligenes xylosoxidans 31A. J Bacteriol 176: 7045-7054.

Shapiro BJ, David LA, Friedman J, Alm EJ. (2009). Looking for Darwin's footprints in the microbial world. Trends Microbiol 17: 196-204.

Shapiro BJ, Friedman J, Cordero OX, Preheim SP, Timberlake SC, Szabo G et al. (2012). Population genomics of early events in the ecological differentiation of bacteria. Science 336: 48-51.

Shapiro BJ, Polz MF. (2014). Ordering microbial diversity into ecologically and genetically cohesive units. Trends Microbiol 22: 235-247.

Smillie CS, Smith MB, Friedman J, Cordero OX, David LA, Alm EJ. (2011). Ecology drives a global network of gene exchange connecting the human microbiome. Nature 480: 241-244.

Sprent JI. (2007). Evolving ideas of legume evolution and diversity: a taxonomic perspective on the occurrence of nodulation. New Phytol 174: 11-25. 
Stapley J, Reger J, Feulner PGD, Smadja C, Galindo J, Ekblom R et al. (2010). Adaptation genomics: the next generation. Trends Ecol Evol 25: 705-712.

Tritt A, Eisen JA, Facciotti MT, Darling AE. (2012). An integrated pipeline for de novo assembly of microbial genomes. PLoS One 7: e42304.

Turner TL, Bourne EC, Wettberg Von EJ, Hu TT, Nuzhdin SV. (2010). Population resequencing reveals local adaptation of Arabidopsis lyrata to serpentine soils. Nat Genet $\mathbf{4 2}$ : U260-U42.

UniProt Consortium. (2015). UniProt: a hub for protein information. Nucleic Acids Res 43: D204-D212.

Zaneveld JRR, Parfrey LW, Van Treuren W, Lozupone C, Clemente JC, Knights D et al. (2011). Combined phylogenetic and genomic approaches for the highthroughput study of microbial habitat adaptation. Trends Microbiol 19: 472-482.
Zhang Z, Li J, Zhao X-Q, Wang J, Wong GK-S Yu J. (2006). KaKs_Calculator: calculating Ka and Ks through model selection and model averaging. Genomics Proteomics Bioinformatics 4: 259-263.

This work is licensed under a Creative Commons Attribution 4.0 International License. The images or other third party material in this article are included in the article's Creative Commons license, unless indicated otherwise in the credit line; if the material is not included under the Creative Commons license, users will need to obtain permission from the license holder to reproduce the material. To view a copy of this license, visit http:// creativecommons.org/licenses/by/4.0/

Supplementary Information accompanies this paper on The ISME Journal website (http://www.nature.com/ismej) 